\title{
Periostin is essential for periodontal ligament remodeling during orthodontic treatment
}

\author{
HUI-YONG XU ${ }^{1,2^{*}}$, ER-MIN NIE ${ }^{3 *}$, GANG DENG $^{4 *}$, LING-ZHI LAI $^{1}$, FENG-YANG SUN $^{1}$, \\ HUA TIAN $^{1}$, FU-CHUN FANG ${ }^{1}$, YA-GUANG ZOU ${ }^{1}$, BU-LING WU ${ }^{1}$ and JUN OU-YANG ${ }^{2}$ \\ ${ }^{1}$ Department of Stomatology, Nanfang Hospital; ${ }^{2}$ Guangdong Provincial Medical Biomechanical Key Laboratory, \\ Department of Anatomy, Southern Medical University, Guangzhou, Guangdong 510515; ${ }^{3}$ Department of \\ Stomatology, The First Affiliated Hospital of Sun Yat-sen University, Guangzhou, Guangdong 510080; \\ ${ }^{4}$ Department of Stomatology, The People's Hospital of Jiaozuo, Jiaozuo, Henan 454002, P.R. China
}

Received December 14, 2015; Accepted December 9, 2016

DOI: $10.3892 / \mathrm{mmr} .2017 .6200$

\begin{abstract}
Orthodontic tooth movement is a process stimulated and maintained by external tensile stress; periodontal ligament remodeling serves an important role during this process. However, the function and underlying mechanism of periostin (PN) during orthodontic periodontal ligament remodeling remain unclear. The present study established in vitro and in vivo models of orthodontic treatment to investigate the expression levels of PN under conditions of external tensile stress load. These results indicated that tensile stress load increased the expression levels of PN in mouse peridontal ligaments and human periodontal ligament cells (hPDLCs), during orthodontic tooth movement. Furthermore, the present study demonstrated that the expression levels of $\mathrm{PN}$ were regulated by transforming grown factor $\beta$, and that PN promotes type I collagen and $\alpha$-smooth muscle actin expression levels in hPDLCs. Therefore, PN may be essential for periodontal ligament remodeling during orthodontic treatment, and therefore may represent a potential therapeutic target.
\end{abstract}

Correspondence to: Dr Jun Ou-Yang, Guangdong Provincial Medical Biomechanical Key Laboratory, Department of Anatomy, Southern Medical University, 1838 North Guangzhou Avenue, Guangzhou, Guangdong 510515, P.R. China

E-mail: jouyang@126.com

Dr Bu-Ling Wu, Department of Stomatology, Nanfang Hospital, Southern Medical University, 1838 North Guangzhou Avenue, Guangzhou, Guangdong 510515, P.R. China

E-mail: bulingwu@smu.edu.cn

*Contributed equally

Abbreviations: $\mathrm{PN}$, periostin; hPDLC, human periodontal ligament cell; FAK, focal adhesion kinase; TGF- $\beta$, transforming growth factor- $\beta$

Key words: periostin, orthodontics, periodontal ligament, remodeling, transforming growth factor- $\beta$

\section{Introduction}

The correction of malocclusion involves adjusting tooth position via external tensile stresses generated by orthodontic appliances, thus causing internal responses to these forces $(1,2)$. During such orthodontic treatments, the periodontal tissues often sustain reversible injury (3). Full rectification of the dentition is only achieved following extensive treatment, due to various factors that may affect a positive outcome (4-6). Despite the development of advanced orthodontic techniques and appliances (7), the underlying mechanisms of orthodontic tooth movement remain unclear.

A previous study has suggested an important role for the periodontal ligament in promoting the movement of teeth and dental implants during orthodontic treatment (8). A variant form of periosteum interposes between the cementum and the alveolar bone; the periodontal ligament consists of dense connective tissue arranged in fiber bundles with the two ends buried in the cementum and the alveolar bone wall socket. In addition to buffering and absorbing external forces (9), the periodontal ligament additionally serves a vital role in the transduction of external forces to promote alveolar bone mineralization and resorption, and repair of injured periodontal tissues (10-12). Dangaria et al (13) demonstrated that stem cell colonies in the periodontal ligament and the extracellular matrix may promote regeneration of periodontal tissues.

A recent study identified periostin (PN) as a critical extracellular matrix protein that functions to regulate the steady state of the periodontal membrane (14). PN is additionally involved in maintaining periodontal tissue integrity, tooth development, external stimuli-induced repair and tissue regeneration, cell adhesion, collagen cross-linking, and fiber formation (15). From a developmental perspective, rat embryos exhibit PN expression on embryonic day 9.5, initially in the first branchial arch, followed by the ectomesenchyme (16), dental papilla cells, and odontoblasts during the bell and hard tissue formation stages. Following birth, PN expression is detected primarily in the fibroblasts of the periodontal ligament and the osteoblasts of the alveolar bone (17).

In the absence of a biting force, the periodontal ligament of Wistar rats becomes weakened and exhibits structural 
alterations, accompanied by a marked decrease in PN mRNA expression levels after $24 \mathrm{~h}$ (18). In PN-knockdown mice, $\mathrm{X}$-ray and micro-computed tomography studies demonstrated no marked alterations in the periodontal ligament during tooth development and eruption, prior to the establishment of normal occlusion, compared with healthy mice. However, in PN-null mice with tooth eruption, significant damages occurred in the periodontal tissue following exposure to a masticatory force for three months (19), suggesting that PN is essential for maintaining the integrity of the periodontal membrane when a biting force is present.

$\mathrm{PN}$ is a multifunctional extracellular matrix protein that may be induced by transforming growth factor- $\beta$ (TGF- $\beta$ ), and serves as a downstream factor of the latter to regulate the synthesis and secretion of collagen in fibroblasts (20). PN secreted by airway epithelial cells may activate TGF- $\beta$ to promote airway fibrosis $(21,22)$. Norris et al (23) demonstrated that in PN-knockout mice, the myocardial collagen has a reduced denaturation temperature. Thus far, little is understood concerning the role of PN in orthodontic periodontal ligament remodeling, and of its association with TGF- $\beta$. The present study aimed to investigate the role of $\mathrm{PN}$ in periodontal ligament remodeling during orthodontic treatment, and the potential underlying molecular mechanisms. This was achieved by detecting PN expression levels under tensile stress conditions, in human periodontal ligament cells (hPDLCs), a mouse model of orthodontic tooth movement and in patients.

\section{Materials and methods}

Subjects. The present study was performed with approval from the Southern Medical University Institutional Research Ethics Committee (Guangzhou, China). Written informed consent was obtained from 25 patients (male, $n=13$; female, $n=12$; age, 18.5 \pm 0.7$)$ who fulfilled the following inclusion criteria: Age, 12-25 years when receiving orthodontic treatment; permanent dentition; normal dentition (with the exception of the third molars); absence of periodontal diseases, severe caries or hyperplasia of the tooth root; absence of systemic diseases and no history of anti-inflammatory agent or immunosuppressant use within 3 months prior to enrollment; willingness to receive reduction tooth extraction of the molars. All the patients received orthodontic treatment in the Orthodontic Department of Nanfang Hospital, Southern Medical University, between June 2012 and December 2013. Of these patients, 10 with crowded dentition but without orthodontic treatment prior to tooth extraction served as the control group, and 15 with normal dentition undergoing orthodontic treatment for 3-4 months constituted the experimental group. The periodontal tissue of tooth roots was removed with a scalpel into a $1.5-\mathrm{ml}$ centrifuge tube and stored at $-80^{\circ} \mathrm{C}$ for further experiments.

Animal experiments. All animal experiments were performed with the approval of Southern Medical University Institutional Research Ethics Committee. Specific pathogen-free male wild-type C57BL/6 mice (age, 4 weeks; weight, $20 \pm 3 \mathrm{~g}$; $\mathrm{n}=35$ ) were obtained from and housed by the Experimental Animal Center of Southern Medical University in standard laboratory conditions $\left(25^{\circ} \mathrm{C}, 10-85 \%\right.$ humidity and a $12 \mathrm{~h}$ light/dark cycle [on at 7:15 a.m. and off at 7:15 p.m.]) with free access to food and water. The mice were randomized into five groups, including a control group without external tensile stress loading, and four experimental groups exposed to $20 \mathrm{~g}$ external tensile stress loading, delivered using a conventional orthodontic method (24) for 2, 4 or 6 days. Using a customized fixed oral traction device, a hook was fixed under a microscope on the incisors of the mouse and a ligature wire that delivered a $20 \mathrm{x} g$ traction force was fixed on the first molars of the mice, which were anesthetized with intravenous sodium pentobarbital (1\%, 35 mg/kg; cat. no. P3761; Sigma-Aldrich; Merck Millipore, Darmstadt, Germany) intravenously injected, and surgical depth of anesthesia was deemed to be achieved when the tail-pinch and pedal withdrawal reflexes were lost (25). The coil spring was kept constant for 2, 4 or 6 days, following which the upper molars exposed to the traction force were removed. The periodontal tissue of the tooth roots was removed with a scalpel and stored in a $1.5-\mathrm{ml}$ centrifuge tube at $-80^{\circ} \mathrm{C}$ for subsequent analysis.

Immunohistochemistry for PN. Following tensile stress loading for various time periods, the five groups of mice were anesthetized with sodium pentobarbital intravenously injected (1\%, 80 mg/kg; cat. no. P376; Sigma-Aldrich; Merck Millipore) and sacrificed by decapitation, and the bone segment containing the first molar and periodontal tissues was harvested. The direction of tensile stress was marked, and the bone segments were fixed with formalin for $6 \mathrm{~h}$ and immersed in decalcifying solution at $4^{\circ} \mathrm{C}$ for 3 weeks. The bone segments were subsequently embedded in paraffin, and for each tissue sample, $3 \mu \mathrm{m}$ thick transverse sections of the upper molars were cut for morphometric analysis. Immunohistochemical staining of the sections was performed using mouse monoclonal anti-PN horseradish peroxidase (HRP) antibody (1:300; cat. no. sc-398631; Santa Cruz Biotechnology, Inc., Dallas, TX, USA). PN expression area and intensity was determined using the labeled streptavidin-biotin technique, as previously described (26). The SP-9000 kit was purchased from ZSGB-BIO (cat. no. SP-9000; Beijing, China). Imaging analysis was conducted using the Image-Pro Plus software version 6.0 (Media Cybernetics, Inc., Rockville, MD, USA).

Cultured hPDLCs and cyclic tensile stress loading. To isolate hPDLCs, healthy wisdom teeth and premolars freshly extracted from young adults for orthodontic reasons were obtained. All the donors were informed of the purpose of the study and written informed consent was given prior to participation. hPDLCs were isolated from the extracted teeth by explant culture combined with enzymatic digestion, as previously described (27). The primary hPDLCs were maintained in Dulbecco's modified Eagle's medium (Gibco; Thermo Fisher Scientific, Inc., Waltham, MA, USA) supplemented with $10 \%$ fetal bovine serum (Gibco; Thermo Fisher Scientific, Inc.), $100 \mathrm{U} / \mathrm{ml}$ penicillin and $100 \mu \mathrm{g} / \mathrm{ml}$ streptomycin at $37^{\circ} \mathrm{C}$ in a humidified atmosphere of $5 \% \mathrm{CO}_{2}$. The cells were dissociated from the surface of the culture flask with trypsin solution [0.25\% trypsin (Gibco; Thermo Fisher Scientific, Inc.), 0.1\% glucose and citrate-saline buffer ( $\mathrm{pH}$ 7.8)] and resuspended for future experiments. The third-passage cells were cultured in a mineralization medium (DMEM supplemented with $10 \%$ FBS, $0.1 \mu \mathrm{M}$ dexamethasome, $50 \mu \mathrm{M}$ vitamin $\mathrm{C}$ and $10 \mathrm{mM}$ 
$\beta$-phosphoglycerol) for 21 days. The cells were subsequently stained with Alizarin Red S to visualize the formation of mineralized nodules, and immunohistochemical staining for vimentin and keratin expression was performed as previously described (26) to ensure that the cells originated from the periodontal ligament instead of the epithelia. Following verification, cells were exposed to cyclic tensile stress loading with a $10 \%$ extent at a $0.5 \mathrm{~Hz}$ resonant frequency delivered from a Flexcell ${ }^{\circledast}$ FX-5000 Tension system (28) for 12, 24 or 48 h. Cells cultured without tensile stress loading under routine conditions served as the control. In order to explore the mechanism of PN during orthodontic periodontal ligament remodeling, hPDLCs were treated with $5 \mathrm{ng} / \mathrm{ml}$ TGF- $\beta$ (cat. no. 11412272001; Roche Applied Science, Penzberg, Germany) for 12, 24 and 48 h (29).

Reverse transcription-quantitative polymerase chain reaction $(R T-q P C R)$. Total RNA from the tensile stress-loaded hPDLCs, periodontal tissues from the mouse model, and patient samples was extracted using TRIzol (Takara Bio, Inc., Otsu, Japan) according to the manufacturer's protocol. The RNA quality was determined using a NanoDrop 2000c Spectrophotometer (Thermo Fisher Scientific, Inc.), and the RNA samples were further analyzed if their absorbance ratio $\left(A_{260} / A_{280}\right)$ was within the range of 1.9-2.1, with a $A_{260} / A_{230}>2$. The RNA was reverse transcribed to cDNA using the RevertAidTM First Strand cDNA Synthesis kit (Fermentas; Thermo Fisher Scientific, Inc.). Primers (Table I; Thermo Fisher Scientific, Inc.) were used to determine the gene expressions of PN, TGF- $\beta$, type I collagen and $\alpha$-smooth muscle actin ( $\alpha$-SMA) by SYBR Green (cat. no. 172-5850; Bio-Rad Laboratories, Hercules, CA, USA) RT-qPCR, and their mRNA expression levels were calculated relative to that of GAPDH. The cycling conditions were as follows: Predenaturation at $94^{\circ} \mathrm{C}$ for $5 \mathrm{~min}$, followed by 40 cycles of denaturation at $95^{\circ} \mathrm{C}$ for $30 \mathrm{sec}$ and annealing at $58^{\circ} \mathrm{C}$ for $30 \mathrm{sec}$. mRNA expression levels were calculated based on the quantification cycle (Cq) (30), and relative expression levels were calculated as $2-[(\mathrm{Cq}$ of target gene)-(Cq of GAPDH)].

Western blotting. The cells exposed to tensile stress loading were analyzed for PN protein expression levels by western blotting. Briefly, the cells in each group were rinsed with phosphate-buffered saline and lysed in radioimmunoprecipitation assay lysis buffer (Beyotime Institute of Biotechnology, Haimen, China) supplemented with protease inhibitors. The total protein was quantified using a Bicinchoninic Acid assay kit (Pierce; Thermo Fisher Scientific, Inc.), according to the manufacturer's protocol. Equal amounts $(30 \mu \mathrm{g})$ of total protein were separated by $10 \%$ SDS-PAGE and subsequently transferred onto polyvinylidene difluoride membranes. The membranes were blocked with $5 \%$ skimmed milk in Tris-buffered saline containing Tween-20 (TBST) for $2 \mathrm{~h}$ at room temperature, and subsequently washed three times ( $5 \mathrm{~min}$ each) in TBST buffer. Following this, the membranes were incubated with the following primary antibodies: Polyclonal mouse anti-human anti-PN (cat. no. sc-398631; 1:500 dilution; Santa Cruz Biotechnology, Inc.), polyclonal mouse anti-human anti-TGF- $\beta$ (cat. no. sc-130348; 1:500 dilution; Santa Cruz Biotechnology, Inc.), mouse anti-type I collagen and mouse anti- $\alpha$-SMA (cat. nos. sc-59772 and sc-53142, respectively;
Table I. Primers for PN, TGF- $\beta$, type I collagen, $\alpha$-SMA and GAPDH.

\begin{tabular}{lcl}
\hline Gene & Direction & \multicolumn{1}{c}{ Sequence (5'-3') } \\
\hline PN & $\mathrm{F}$ & GAGACAAAGTGGCTTCCG \\
& $\mathrm{R}$ & CTGTCACCGTCACATCCT \\
TGF- $\beta$ & $\mathrm{F}$ & GCAACAATTCCTGGCGATAC \\
& $\mathrm{R}$ & AAGGCGAAAGCCCTCAAT \\
Type I & $\mathrm{F}$ & GAGGGCCAAGACGAAGACATC \\
collagen & & \\
& $\mathrm{R}$ & CAGATCACGTCATCGCACAAC \\
$\alpha$-SMA & $\mathrm{F}$ & GGCATTCACGAGACCACCTAC \\
& $\mathrm{R}$ & CGACATGACGTTGTTGGCATAC \\
GAPDH & $\mathrm{F}$ & ACAGTCAGCCGCATCTTCTT \\
& $\mathrm{R}$ & GACAAGCTTCCCGTTCTCAG
\end{tabular}

PN, periostin; TGF- $\beta$, transforming growth factor- $\beta$; $\alpha$-SMA, $\alpha$ smooth muscle actin; F, forward; R, reverse.

1:500 dilution; Santa Cruz Biotechnology, Inc.), with gentle agitation overnight at $4^{\circ} \mathrm{C}$. The membranes were subsequently incubated with goat anti-mouse HRP-conjugated secondary antibodies (cat. no. A4416; 1:3,000 dilution; Sigma-Aldrich; Merck Millipore) for 45 min with gentle rocking at room temperature prior to membrane washing with TBST buffer. Mouse monoclonal anti- $\alpha$-tubulin (cat. no. T9026; 1:1,000 dilution; Sigma-Aldrich; Merck Millipore) served as the loading control. Chemiluminescence was detected using SuperSignal West Femto Maximum Sensitivity Substrate (Pierce; Thermo Fisher Scientific, Inc.) in a ChemiDocXRS system (Bio-Rad Laboratories, Inc.) and Quantity One 1-D Analysis Software (version 1709600; Bio-Rad Laboratories, Inc.).

Statistical analysis. Data are expressed as the mean \pm standard error and were analyzed with SPSS software version 13.0 (SPSS, Inc., Chicago, IL, USA). Data were tested for normal distribution and/or homogeneity variance prior to comparisons between groups and analyses were performed by one-way analysis of variance. Least significant difference or Dunnett's T3 post hoc tests were used to compare the differences between the control and treatment groups. $\mathrm{P}<0.05$ was considered to indicate a statistically significant difference.

\section{Results}

Tensile stress load increases PN expression levels in hPDLCs. Compared with control cells, which demonstrated a radial pattern of cell proliferation, hPDLCs exposed to cyclic tensile stress of $10 \%$ extent at $0.5 \mathrm{~Hz}$ exhibited a fence-like and parallel growth pattern, consistent with the direction of tensile stress (Fig. 1A). To investigate the role of $\mathrm{PN}$ in this process, mRNA (Fig. $1 \mathrm{~B} ; \mathrm{P}<0.05$ ) and protein (Fig. 1C; $\mathrm{P}<0.05$ ) expression levels of $\mathrm{PN}$ were analyzed in cells following tensile stress loading. RT-qPCR and western blotting results revealed that cyclic tensile stress induced a time-dependent increase of PN mRNA and protein expression levels in hPDLCs. 
$\mathbf{A}$

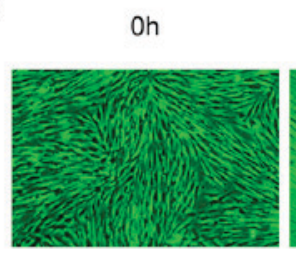

C

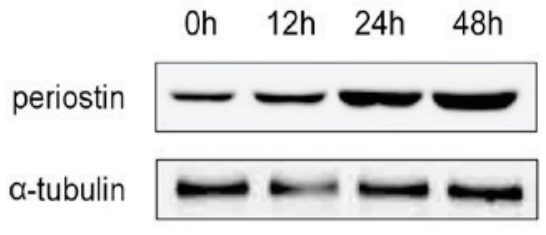

$48 \mathrm{~h}$

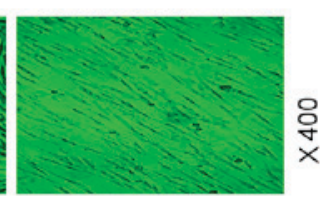

$\stackrel{\substack{+\times}}{\times}$
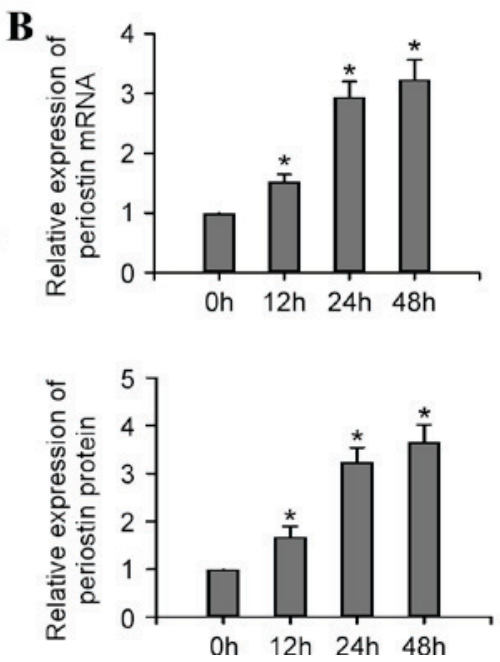

Figure 1. PN expression levels in hPDLCs following tensile stress load. (A) Morphology and growth status of hPDLCs exposed to tensile stress load (48 $\mathrm{h}$ ) and control hPDLCs $(0 \mathrm{~h})$. Quantification of (B) mRNA and (C) protein expression levels of PN in hPDLCs following exposure to tensile stress for $0,12,24 \mathrm{or} 48 \mathrm{~h}$. Data are presented as the mean \pm standard error. "P<0.05 vs. 0 h. PN, periostin; hPLCs, human periodontal ligament cells.

PN expression levels increase in mouse periodontal ligaments during orthodontic tooth movement. In a mouse model of orthodontic tooth movement, PN mRNA expression levels in the periodontal ligament increased with tensile stress loading in a time-dependent manner (Fig. 2A; $\mathrm{P}<0.05$ ). Immunohistochemistry revealed a diffuse pattern of PN distribution in the periodontal ligament of healthy mice. Mice subjected to tensile stress loading demonstrated a time-dependent increase in PN staining intensity in the periodontal ligament during the first 4 days (Fig. 2B), whereas at 6 days, the staining expression intensity had decreased, suggesting that PN was involved in the entire process of periodontal ligament remodeling induced by the external force, and that its expression levels increased as the duration of the external force extended.

PN mRNA expression levels increase in human periodontal ligament during orthodontic tooth movement. The 15 patients who received preceding orthodontic treatment all exhibited significantly upregulated PN mRNA (Fig. 3A; P<0.05) and protein (Fig. 3B; $\mathrm{P}<0.05$ ) expression levels in the periodontal ligament of the extracted teeth, compared with those who did not receive orthodontic treatment. This result demonstrated an important role for PN in periodontal ligament remodeling during orthodontic treatment.

TGF- $\beta$ increases PN expression levels and promotes type I collagen and $\alpha$-SMA expression. Due to the association between PN and TGF- $\beta$, the present study investigated whether the TGF- $\beta$ signaling pathway regulates PN expression levels in hPDLCs, and how PN regulates type I collagen during periodontal ligament remodeling. It was demonstrated that PN and TGF- $\beta$ expression levels were upregulated in parallel in hPDLCs exposed to cyclic tensile stress loading (Fig. 4A; P<0.05). In addition, hPDLCs cultured in the presence of TGF- $\beta$ without tensile stress loading exhibited a time-dependent increase in PN mRNA expression levels (Fig. 4B; $\mathrm{P}<0.05$ ), and the expression of $\mathrm{PN}$ was in parallel with the protein and mRNA expression
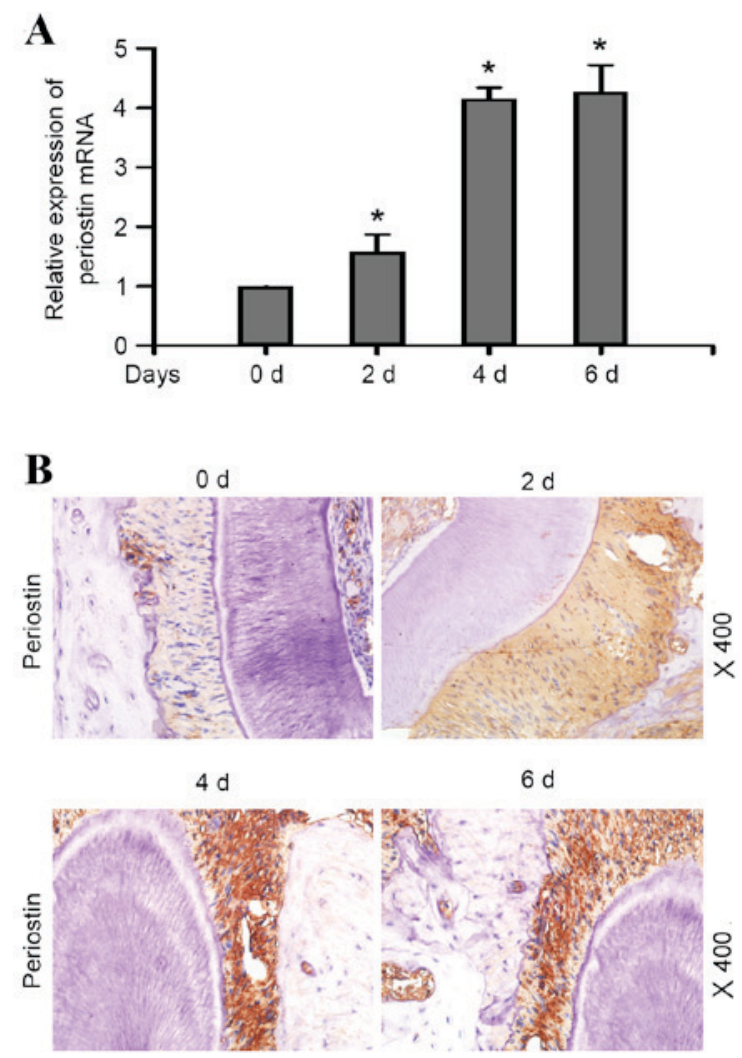

Figure 2. PN expression levels in a mouse model of orthodontic tooth movement. (A) Quantification of PN mRNA expression levels following tensile stress load. Data are presented as the mean \pm standard error. ${ }^{*} \mathrm{P}<0.05$ vs. 0 days. (B) Immunohistochemical staining of the upper molars exposed to $20 \mathrm{~g}$ force for $0,2,4$ or 6 days. PN expression intensity increased in a time-dependent manner. Magnification, $\mathrm{x} 400$. PN, periostin.

of type I collagen and $\alpha$-SMA in hPDLCs treated with TGF- $\beta$ (Fig. $4 C ; P<0.05$ ). Taken together, these results indicated that PN upregulated by TGF- $\beta$ might stimulate the expression of type I collagen and $\alpha$-SMA, thus contributing to periodontal ligament remodeling during orthodontic treatment. 
A

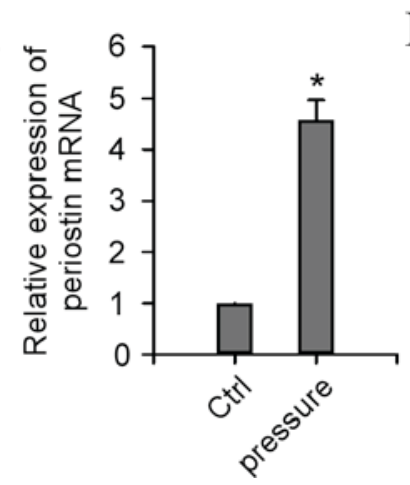

B

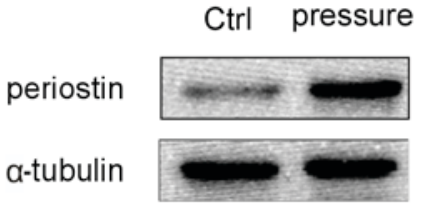

Figure 3. PN expression levels in human periodontal ligaments. (A) Quantification of PN mRNA expression levels, as determined by reverse transcription-quantitative polymerase chain reaction. (B) Representative western blot images and quantification of PN protein expression levels in human periodontal ligaments in control and experimental groups. mRNA and protein expression levels significantly increased in the experimental group, compared with the control group. Data are presented as the mean \pm standard error. ${ }^{*} \mathrm{P}<0.05$. PN, periostin; Ctrl, control.

A
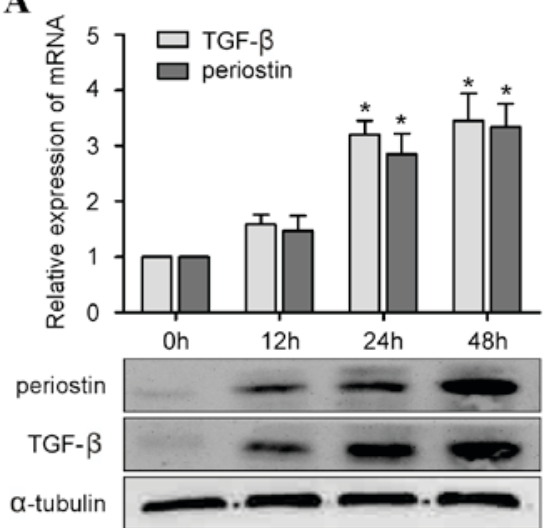

C

periostin

a-SMA

Oh

$12 \mathrm{~h}$

$24 \mathrm{~h}$

$48 \mathrm{~h}$

collagen I

a-tubulin
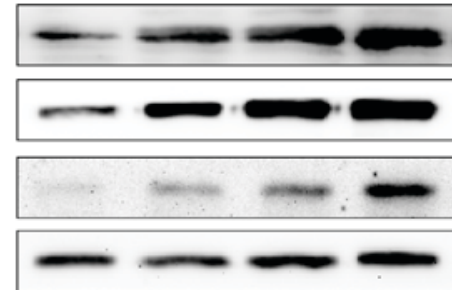

B
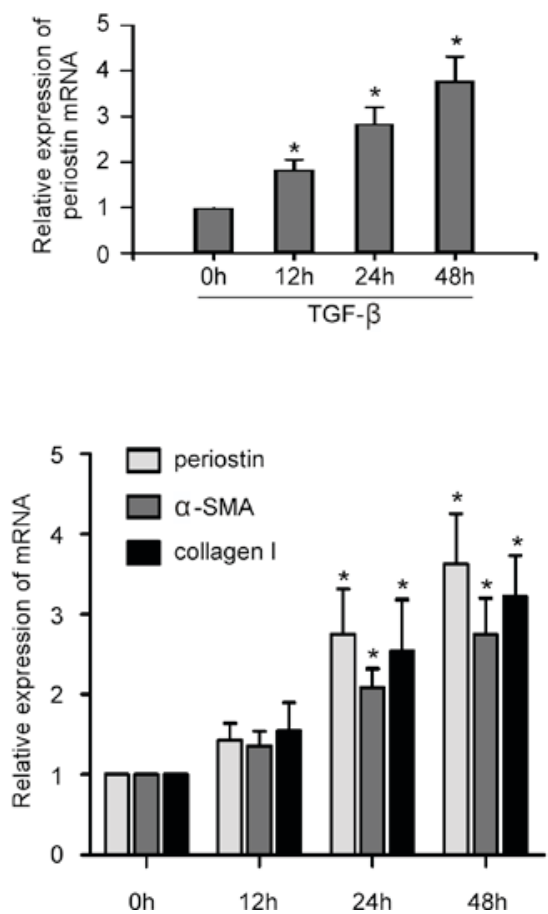

Figure 4. Alterations in expression levels of PN, TGF- $\beta$, type I collagen and $\alpha$-SMA over time in hPDLCs. (A) Reverse transcription-quantitative polymerase chain reaction quantification and representative western blot images of PN and TGF- $\beta$ mRNA and protein expression levels in hPDLCs, respectively, upon exposure to $0,12,24$ or 48 h external tensile stress. (B) PN mRNA expression levels in hPDLCs were upregulated by TGF- $\beta$ in a time-dependent manner. (C) Type I collagen and $\alpha$-SMA protein and mRNA expression levels increased with PN expression levels in hPDLCs treated with 5 ng/ml TGF- $\beta$, in a time-dependent manner. Data are presented as the mean \pm standard error. ${ }^{*} \mathrm{P}<0.05$ vs. 0 h. PN, periostin; TGF- $\beta$, transforming growth factor- $\beta$, $\alpha-$ SMA, $\alpha$-smooth muscle actin; hPLCs, human periodontal ligament cells.

\section{Discussion}

As extracellular matrix proteins have been identified to serve important functions in multiple systems of the human body, PN has been increasingly investigated (31-36). An anti-PN antibody has been developed for use in cancer treatment (37), and recombinant PN constructs have been assessed in mice to induce angiogenesis (38), and to stimulate myocardial regeneration in large mammals (39). Previous studies have demonstrated a criticial role of $\mathrm{PN}$ as a tissue biomarker in the periodontal ligament $(15,40)$; however, the precise underlying mechanisms of its effects and its potential value in clinical orthodontic treatment remain to be clarified.

In the present study, the function of PN during orthodontic treatment was investigated by assessing PN expression levels in response to external tensile stress load in vitro and in vivo. These results supported the hypothesis that PN serves an important role in periodontal remodeling during orthodontic tooth movement. Notably, results from patient samples further demonstrated the potential clinical applications of PN.

Wen et al (41) demonstrated that TGF- $\beta$ significantly increased PN mRNA expression levels in periodontal ligament 
fibroblasts, and that this effect was attenuated by focal adhesion kinase (FAK) inhibitors; in FAK knockout fibroblasts, no PN mRNA was detected even following cyclic stress stimulation. PN may additionally be chemotactic for myocardial fibroblasts via $\alpha \mathrm{V}$-integrin-induced phosphorylation of FAK and protein kinase B $(42,43)$. The present study revealed that in hPDLCs exposed to tensile stress, PN and TGF- $\beta$ expression levels increased in parallel. These results suggested that the TGF- $\beta /$ FAK-dependent pathway may participate in the regulation of $\mathrm{PN}$ in the periodontal ligament.

PN has previously been demonstrated to promote angiogenesis by upregulating matrix metalloproteinase- 2 mediated by $\alpha \mathrm{V} \beta 3$ integrin/extracellular signal-regulated kinase signaling and vascular endothelial growth factor; the latter was additionally revealed to be present in human periodontal ligaments (44). Under stress conditions, PN may bind to a Notchl precursor that inhibits cell apoptosis by upregulating B-cell lymphoma-extra large (45). TGF- $\beta$ has been reported to regulate the mRNA expression of type I collagen and $\alpha$-SMA in human PDL cells (29). Based on these observations, it is possible to speculate that as a downstream target of TGF- $\beta$, PN regulates type I collagen and $\alpha$-SMA expression to affect the mechanical properties of the periodontal ligament and serves as a marker of periodontal ligament remodeling $(46,47)$. These findings indicate the versatile functions of PN in periodontal ligament remodeling and in numerous other disease conditions, including proliferative vitreoretinopathy (48) and certain cancers (49). However, the complex mechanisms underlying its functions remain to be further investigated.

In conclusion, the present study demonstrated that PN serves a crucial role in periodontal ligament remodeling during orthodontic treatment, and may be associated with TGF- $\beta$, type I collagen and $\alpha$-SMA expression. These results suggested the value of $\mathrm{PN}$ as a potential therapeutic target for the treatment of malocclusion.

\section{Acknowledgements}

The present study was supported by the National Natural Science Foundation of China (Beijing, China; grant no. 81371137) and the Natural Science Foundation of Guangdong Province (Guangzhou, China; grant no. 2015A030310140).

\section{References}

1. Rody WJ Jr, King GJ and Gu G: Osteoclast recruitment to sites of compression in orthodontic tooth movement. Am J Orthod Dentofacial Orthop 120: 477-489, 2001.

2. Wise GE and King GJ: Mechanisms of tooth eruption and orthodontic tooth movement. J Dent Res 87: 414-434, 2008.

3. Rafiuddin S, Yg PK, Biswas S, Prabhu SS, Bm C and Mp R: Iatrogenic damage to the periodontium caused by orthodontic treatment procedures: An overview. Open Dent J 9: 228-234, 2015.

4. Prasad RV, Chincholi S, V D, Sirajuddin S, Biswas S, Prabhu SS and Mp R: Iatrogenic factors affecting the periodontium: An overview. Open Dent J 9: 208-209, 2015.

5. Ryan FS, Moles DR, Shute JT, Clarke A and Cunningham SJ: Social anxiety in orthognathic patients. Int J Oral Maxillofac Surg 45: 19-25, 2016.

6. Pachêco-Pereira C, Abreu LG, Dick BD, De Luca Canto G, Paiva SM and Flores-Mir C: Patient satisfaction after orthodontic treatment combined with orthognathic surgery: A systematic review. Angle Orthod 86: 495-508, 2016.
7. Yang X, Zhu Y, Long H, Zhou Y, Jian F, Ye N, Gao M and Lai W: The effectiveness of the Herbst appliance for patients with Class II malocclusion: A meta-analysis. Eur J Orthod 38: 324-333, 2016.

8. Romanos GE, Asnani KP, Hingorani D and Deshmukh VL: PERIOSTIN: Role in formation and maintenance of dental tissues. J Cell Physiol 229: 1-5, 2014

9. Beertsen W, McCulloch CA and Sodek J: The periodontal ligament: A unique, multifunctional connective tissue. Periodontology 2000 13: 20-40, 1997.

10. Jessop HL, Rawlinson SC, Pitsillides AA and Lanyon LE: Mechanical strain and fluid movement both activate extracellular regulated kinase (ERK) in osteoblast-like cells but via different signaling pathways. Bone 31: 186-194, 2002.

11. McAllister TN and Frangos JA: Steady and transient fluid shear stress stimulate NO release in osteoblasts through distinct biochemical pathways. J Bone Miner Res 14: 930-936, 1999.

12. Bakker AD, Soejima K, Klein-Nulend J and Burger EH: The production of nitric oxide and prostaglandin $\mathrm{E}(2)$ by primary bone cells is shear stress dependent. J Biomech 34: 671-677, 2001.

13. Dangaria SJ, Ito Y, Walker C, Druzinsky R, Luan X and Diekwisch TG: Extracellular matrix-mediated differentiation of periodontal progenitor cells. Differentiation 78: 79-90, 2009.

14. Padial-Molina M, Volk SL and Rios HF: Preliminary insight into the periostin leverage during periodontal tissue healing. J Clin Periodontol: Jul 23, 2015 (Epub ahead of print).

15. Padial-Molina M, Volk SL, Rodriguez JC, Marchesan JT, Galindo-Moreno P and Rios HF: Tumor necrosis factor- $\alpha$ and Porphyromonas gingivalis lipopolysaccharides decrease periostin in human periodontal ligament fibroblasts. J Periodontol 84: 694-703, 2013

16. Kruzynska-Frejtag A, Wang J, Maeda M, Rogers R, Krug E Hoffman S, Mark wald RR and Conway SJ: Periostin is expressed within the developing teeth at the sites of epithelial-mesenchymal interaction. Dev Dyn 229: 857-868, 2004.

17. Wilde J, Yokozeki M, Terai K, Kudo A and Moriyama K: The divergent expression of periostin $\mathrm{mRNA}$ in the periodontal ligament during experimental tooth movement. Cell Tissue Res 312: 345-351, 2003.

18. Choi JW, Arai C, Ishikawa M, Shimoda S and Nakamura Y: Fiber system degradation, and periostin and connective tissue growth factor level reduction, in the periodontal ligament of teeth in the absence of masticatory load. J Periodontal Res 46: 513-521, 2011.

19. Rios HF, Ma D, Xie Y, Giannobile WV, Bonewald LF, Conway SJ and Feng JQ: Periostin is essential for the integrity and function of the periodontal ligament during occlusal loading in mice. J Periodontol 79: 1480-1490, 2008.

20. Stambolic V and Woodgett JR: Functional distinctions of protein kinase B/Akt isoforms defined by their influence on cell migration. Trends Cell Biol 16: 461-466, 2006.

21. Sidhu SS, Yuan S, Innes AL, Kerr S, Woodruff PG, Hou L, Muller SJ and Fahy JV: Roles of epithelial cell-derived periostin in TGF-beta activation, collagen production, and collagen gel elasticity in asthma. Proc Natl Acad Sci USA 107: 14170-14175, 2010.

22. Gordon ED, Sidhu SS, Wang ZE, Woodruff PG, Yuan S, Solon MC, Conway SJ, Huang X, Locksley RM and Fahy JV: A protective role for periostin and TGF- $\beta$ in IgE-mediated allergy and airway hyperresponsiveness. Clin Exp Allergy 42: 144-155, 2012.

23. Norris RA, Borg TK, Butcher JT, Baudino TA, Banerjee I and Markwald RR: Neonatal and adult cardiovascular pathophysiological remodeling and repair: developmental role of periostin. Annals of the New York Academy of Sciences 1123: 30-40, 2008.

24. Alobeid A, Dirk C, Reimann S, El-Bialy T, Jäger A and Bourauel C: Mechanical properties of different esthetic and conventional orthodontic wires in bending tests: An in vitro study. J Orofac Orthop: Dec 9, 2016 (Epub ahead of print).

25. Burnside WM, Flecknell PA, Cameron AI and Thomas AA: A comparison of medetomidine and its active enantiomer dexmedetomidine when administered with ketamine in mice. BMC Vet Res 9: 48, 2013.

26. Shin M, Izumi S and Nakane PK: Multilayer peroxidase-labeled antibody method: Comparison with labeled streptavidin-biotin method, avidin-biotin-peroxidase complex method, and peroxidase-antiperoxidase method. J Clin Lab Anal 9: 424-430, 1995.

27. Silverio-Ruiz KG, Martinez AE, Garlet GP, Barbosa CF, Silva JS, Cicarelli RM, Valentini SR, Abi-Rached RS and Junior CR: Opposite effects of bFGF and TGF-beta on collagen metabolism by human periodontal ligament fibroblasts. Cytokine 39: 130-137, 2007. 
28. Wei FL, Wang JH, Ding G, Yang SY, Li Y, Hu YJ and Wang SL: Mechanical force-induced specific MicroRNA expression in human periodontal ligament stem cells. Cells Tissues Organs 199: 353-363, 2014.

29. Watanabe T, Yasue A and Tanaka E: Hypoxia-inducible factor-1 $\alpha$ is required for transforming growth factor- $\beta 1$-induced type I collagen, periostin and $\alpha$-smooth muscle actin expression in human periodontal ligament cells. Arch Oral Biol 59: 595-600, 2014.

30. Livak KJ and Schmittgen TD: Analysis of relative gene expression data using real-time quantitative PCR and the 2(-Delta Delta C(T)) Method. Methods 25: 402-408, 2001.

31. Takayama I, Kii I and Kudo A: Expression, purification and characterization of soluble recombinant periostin protein produced by Escherichia coli. J Biochem 146: 713-723, 2009.

32. Daines SM, Wang Y and Orlandi RR: Periostin and osteopontin are overexpressed in chronically inflamed sinuses. Int Forum Allergy Rhinol 1: 101-105, 2011.

33. Dobreva MP, Lhoest L, Pereira PN, Umans L, Camus A, Chuva de Sousa Lopes SM and Zwijsen A: Periostin as a biomarker of the amniotic membrane. Stem Cells Int 2012: 987185, 2012.

34. Wang X, Liu J, Wang Z, Huang Y, Liu W, Zhu X, Cai Y, Fang X, Lin S, Yuan L and Ouyang G: Periostin contributes to the acquisition of multipotent stem cell-like properties in human mammary epithelial cells and breast cancer cells. PLoS One 8 e72962, 2013.

35. Arima K, Ohta S, Takagi A, Shiraishi H, Masuoka M, Ontsuka K, Suto H, Suzuki S, Yamamoto K, Ogawa M, et al: Periostin contributes to epidermal hyperplasia in psoriasis common to atopic dermatitis. Allergol Int 64: 41-48, 2015.

36. Sorocos K, Kostoulias X, Cullen-McEwen L, Hart AH, Bertram JF and Caruana G: Expression patterns and roles of periostin during kidney and ureter development. J Urol 186 : 1537-1544, 2011

37. Kyutoku M, Taniyama Y, Katsuragi N, Shimizu H, Kunugiza Y, Iekushi K, Koibuchi N, Sanada F, Oshita Y and Morishita R: Role of periostin in cancer progression and metastasis: Inhibition of breast cancer progression and metastasis by anti-periostin antibody in a murine model. Int J Mol Med 28: 181-186, 2011.

38. Kim BR, Jang IH, Shin SH, Kwon YW, Heo SC, Choi EJ, Lee JS and Kim JH: Therapeutic angiogenesis in a murine model of limb ischemia by recombinant periostin and its fasciclin I domain. Biochim Biophys Acta 1842: 1324-1332, 2014.
39. Ladage D, Yaniz-Galende E, Rapti K, Ishikawa K, Tilemann L, Shapiro S, Takewa Y, Muller-Ehmsen J, Schwarz M, Garcia MJ, et al: Stimulating myocardial regeneration with periostin Peptide in large mammals improves function post-myocardial infarction but increases myocardial fibrosis. PLoS One 8: e59656, 2013.

40. Horiuchi K, Amizuka N, Takeshita S, Takamatsu H, Katsuura M, Ozawa H, Toyama Y, Bonewald LF and Kudo A: Identification and characterization of a novel protein, periostin, with restricted expression to periosteum and periodontal ligament and increased expression by transforming growth factor beta. J Bone Miner Res 14: 1239-1249, 1999.

41. Wen W, Chau E, Jackson-Boeters L, Elliott C, Daley TD and Hamilton DW: TGF-ss1 and FAK regulate periostin expression in PDL fibroblasts. Journal of Dental Research 89: 1439-1443, 2010.

42. Mitra SK, Hanson DA and Schlaepfer DD: Focal adhesion kinase: In command and control of cell motility. Nat Rev Mol Cell Biol 6: 56-68, 2005.

43. Hakuno D, Takahashi T, Lammerding J and Lee RT: Focal adhesion kinase signaling regulates cardiogenesis of embryonic stem cells. J Biol Chem 280: 39534-39544, 2005.

44. Watanabe T, Yasue A, Fujihara S and Tanaka E: PERIOSTIN regulates MMP-2 expression via the $\alpha v \beta 3$ integrin/ERK pathway in human periodontal ligament cells. Arch Oral Biol 57: 52-59, 2012.

45. Tanabe H, Takayama I, Nishiyama T, Shimazaki M, Kii I, Li M, Amizuka N, Katsube K and Kudo A: Periostin associates with Notch1 precursor to maintain Notch1 expression under a stress condition in mouse cells. PLoS One 5: e12234, 2010.

46. Kaku M and Yamauchi M: Mechano-regulation of collagen biosynthesis in periodontal ligament. J Prosthodont Res 58: 193-207, 2014.

47. Olson C, Uribe F, Kalajzic Z, Utreja A, Nanda R, Rowe D and Wadhwa S: Orthodontic tooth movement causes decreased promoter expression of collagen type 1 , bone sialoprotein and alpha-smooth muscle actin in the periodontal ligament. Orthod Craniofac Res 15: 52-61, 2012.

48. Ishikawa K: Periostin in the pathogenesis of proliferative vitreoretinopathy. Nippon Ganka Gakkai Zasshi 119: 772-780, 2015 (In Japanese).

49. Qin X, Yan M, Zhang J, Wang X, Shen Z, Lv Z, Li Z, Wei W and Chen W: TGF 33 -mediated induction of Periostin facilitates head and neck cancer growth and is associated with metastasis. Sci Rep 6: 20587, 2016. 